\title{
Satellite-Based Monitoring of Annual Coastal Reclamation in Shenzhen and Hong Kong since the 21st Century: A Comparative Study
}

\author{
Tanxin Feng ${ }^{1}$ and $\mathrm{Nan} X \mathrm{u}^{2, *}$ \\ 1 College of Earth Science, Chengdu University of Technology, Chengdu 610051, China; \\ fengtanxin@stu.cdut.edu.cn \\ 2 College of Marine Science and Engineering, Nanjing Normal University, Nanjing 210023, China \\ * Correspondence: 76005@njnu.edu.cn; Tel.: +86-15380508199
}

Citation: Feng, T.; Xu, N

Satellite-Based Monitoring of Annual Coastal Reclamation in Shenzhen and Hong Kong since the 21st Century: A Comparative Study. J. Mar. Sci. Eng 2021, 9, 48. https://doi.org/10.3390/ jmse9010048

Received: 30 November 2020 Accepted: 31 December 2020 Published: 5 January 2021

Publisher's Note: MDPI stays neutral with regard to jurisdictional clai$\mathrm{ms}$ in published maps and institutional affiliations.

Copyright: (C) 2021 by the authors. Licensee MDPI, Basel, Switzerland. This article is an open access article distributed under the terms and conditions of the Creative Commons Attribution (CC BY) license (https:// creativecommons.org/licenses/by/ $4.0 /)$

\begin{abstract}
To solve the shortage of land resources, many coastal cities have implemented coastal reclamation projects over the past few decades. Coastal reclamation can promote the economic development of coastal cities and improve human well-being in coastal zones. However, it can inevitably cause a series of ecological and environmental issues, such as coastal water pollution, ecosystem destruction, habitat loss, and land subsidence. Shenzhen and Hong Kong are two large neighboring Chinese coastal cities in southern China with different systems. As densely populated and economically developed cities, they face similar land shortage issues. However, recent coastal reclamation changes in Shenzhen and Hong Kong are unclear under different social and political systems. To fill this gap, this study aimed to monitor and compare recent annual coastal reclamation in Shenzhen and Hong Kong with totally different systems using free and open satellite products. Then, to compare the results of coastal reclamation between Shenzhen and Hong Kong. Largescale coastal reclamation in Shenzhen and Hong Kong from 2000 to 2018 can be observed. The total area of coastal reclamation was $4140.7 \mathrm{hm}^{2}$, of which the total coastal reclamation area in Shenzhen was $3409.8 \mathrm{hm}^{2}$ and the total coastal reclamation area in Hong Kong was $730.9 \mathrm{hm}^{2}$. Coastal reclamation in Shenzhen showed a temporal characteristic of "increasing slightly and then decreasing sharply". Before and after 2010, the area of accumulated coastal reclamation were $3202.9 \mathrm{hm}^{2}$ and $206.9 \mathrm{hm}^{2}$. Comparatively, coastal reclamation in Hong Kong exhibited a temporal characteristic of "first decreasing and then increasing and then decreasing". In 2002 and 2014, the scale of coastal reclamation was relatively large, with a total area of $501.8 \mathrm{hm}^{2}$, accounting for $69.19 \%$ of its total area of coastal reclamation. The comparison between our produced coastal reclamation and the official area on coastal reclamation exhibited a good agreement based on correlation analysis $(r=0.99)$ and RMSE (Root Mean Square Error) (0.72). Since the 21st century, Shenzhen and Hong Kong have shown different, even opposite, policies on coastal reclamation. It will be necessary to continuously monitor future coastal reclamation driven by policies for better conducting sustainable coastal development in the Guangdong-Hong Kong-Macao Greater Bay Area.
\end{abstract}

Keywords: coastal reclamation; Shenzhen; Hong Kong; satellite; remote sensing; landsat

\section{Introduction}

In recent years, with the continuous development of urbanization and industrialization, the demand for land resources has increased over time [1]. To alleviate the shortage of land resources, many coastal countries around the world, such as the Netherlands [2], Italy [3], Japan [4], and Singapore [5], have gained a large amount of land from coastal reclamation activities. China began coastal reclamation activities in the 1950s and 1960s, and by the end of the last century, the area of coastal reclamation in China reached $12,000 \mathrm{~km}^{2}$ with an average of 230 to $240 \mathrm{~km}^{2}$ of reclamation per year, and over $30 \%$ of tidal land reclaimed [6]. There are many purposes for coastal reclamation, such as population living, 
freight transportation, industrial production, agricultural planting, and recreation, which have brought huge benefits to urban development and people's lives [7]. However, coastal reclamation has also brought many potential threats to coastal zones, such as coastal water pollution [8], habitat loss, ecosystem destruction [9], and land subsidence [10], which have threatened human well-being and economic development [11]. Therefore, spatial coverage and temporal changes of coastal reclamation can serve as fundamental data for policy-making on biological conservation, environmental protection, and sustainable development in coastal zones.

Shenzhen is the first special economic zone in China and its economy has grown rapidly since the reform and opening up, 40 years ago. To meet the land resource demand for rapid urbanization, Shenzhen has launched many coastal reclamation projects since the establishment of the Special Economic Zone in 1980 [12]. In particular, it was a period of rapid growth in Shenzhen coastal reclamation from the mid-1990s to the end of the 1990s with an annual average reclamation of $337.16 \mathrm{hm}^{2}$ [13]. The history of coastal reclamation in Hong Kong is longer when compared with Shenzhen. Since the mid-19th century, many coastal reclamation projects have been conducted [14]. Over the past 100 years, Hong Kong has intermittently conducted many coastal reclamation activities dozens of times, reaching the peak of coastal reclamation in the 1990s. By 2014, coastal reclamation in Hong Kong has exceeded $67 \mathrm{~km}^{2}$, accounting for more than $6 \%$ of the total land area of Hong Kong [15]. From the 21st century to the present, to promote environmental protection, the coastal reclamation in Shenzhen and Hong Kong has entered a stage of rational growth and the rate of coastal reclamation has declined significantly [13]. However, after 2018, to promote economic development and solve the housing tension problem, the Hong Kong government re-planned coastal reclamation, which means that the area of coastal reclamation in Hong Kong may increase largely in the future.

In many previous studies, remotely sensed data have been widely used to study coastal reclamation in Shenzhen and Hong Kong. Hong, et al. used Landsat images to interpret the dynamics of reclamation in Shenzhen from 1979 to 2014 at 10-year intervals and analyzed the influencing factors [16]. Wu used Landsat images to extract Shenzhen coastline data from 1988 to 2015 at 6-year intervals [17]. Fung used Landsat MSS and SPOT High Resolution Visible (HRV) data to produce a map of Hong Kong's expansion from 1979 to 1987 [18]. These studies used several remote sensing images to monitor coastal reclamation in Shenzhen and Hong Kong at an interval of several years. However, none of these studies obtained detailed information on coastal reclamation in Shenzhen and Hong Kong on an annual scale, which is essential for tracking coastal reclamation with massive and rapid expansion [19-22]. It is necessary to monitor coastal reclamation changes at an annual scale to obtain specific years of coastal reclamation projects, which are lost in previous studies.

In this study, Landsat data and the Joint Research Centre Global Surface Water (GSW) dataset [23] from 1999 to 2018 were combined to track annual coastal reclamation changes in Shenzhen and Hong Kong under totally different social and political systems since the 21st century for a comparative study. Then, we analyzed and compared the spatial distribution and temporal changes of coastal reclamation in Shenzhen and Hong Kong from 2000 to 2018. Google Maps in 2019 was also used to help manually interpret the types and utilization of coastal reclamation in our study area. Moreover, we validated our result by comparing it with the statistics of coastal reclamation provided by Hong Kong officials (detailed in Section 2.2 Data Source).

\section{Study Area and Data Sources}

\subsection{Study Area}

Shenzhen and Hong Kong were selected as our study area. Shenzhen and Hong Kong are located in the Pearl River Delta, belonging to the Guangdong-Hong Kong-Macao Greater Bay Area (GBA). Shenzhen is located on the seashore of Guangdong Province of southern China. It faces Daya Bay and Dapeng Bay in the east and borders Pearl River 
Estuary and Lingding Channel in the west. It connects Hong Kong by the Shenzhen River to the south and borders Dongguan and Huizhou in the north. Although they are two large neighboring Chinese coastal cities, they have totally different systems. Specifically, Shenzhen has a socialist system while Hong Kong has a capitalist system. After the reform and opening up, as a special economic zone, Shenzhen's economy has been developing rapidly since the 1980s. Comparatively, Hong Kong developed as a warehousing and distribution center for U.K. trade with southern China since 1842 after the Treaty of Nanking. Although Shenzhen's social and economic development is far behind that of Hong Kong, Shenzhen exhibits a higher development speed. According to the Shenzhen China website [24], by the end of 2018, Shenzhen had a total land area of $1997 \mathrm{~km}^{2}$, a total sea area of $1145 \mathrm{~km}^{2}$, a coastline length of $260 \mathrm{~km}$, and a total population of 13 million. Shenzhen is dominated by mountainous areas with few plains. Since the reform and opening up, rapid economic development has led to a significant problem of land scarcity. The limitation of land has become an important factor that restricts the development of Shenzhen [25]. Hong Kong is on the south side of Shenzhen and it is composed of the Hong Kong Island, Kowloon Peninsula, the inland area of the New Territories, and 262 small islands. According to the Hong Kong Lands Department [26] and the Hong Kong Census and Statistics Department [27], by the end of 2018, Hong Kong had a total land area of $1106 \mathrm{~km}^{2}$, a total sea area of $1648.7 \mathrm{~km}^{2}$, a coastline length of about $360 \mathrm{~km}$, and a total population of 7.5 million. Hong Kong has one of the highest construction density worldwide due to large-scale urban development and limited land resources [28]. Figure 1 shows the map of our study area (i.e., Shenzhen and Hong Kong).

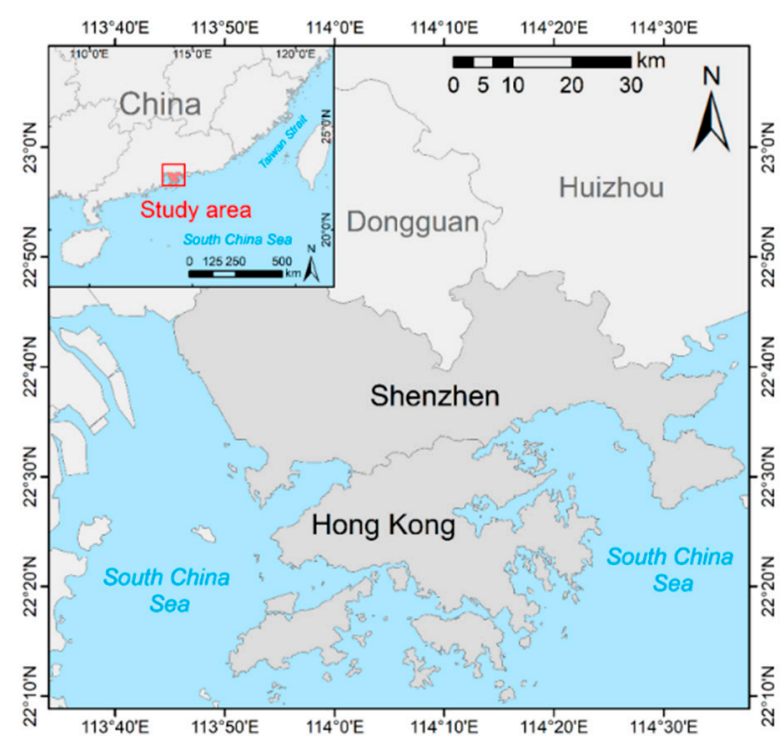

Figure 1. Map of the study area (i.e., Shenzhen and Hong Kong). In the inset, the red box indicates the location of the study area.

\subsection{Data Sources}

In this study, three data sources (i.e., Landsat imagery, GSW dataset (Table 1), and the Hong Kong Reclamation Map) were used to monitor annual coastal reclamation in Shenzhen and Hong Kong since the 21st century. Landsat imagery was used for visual interpretation to extract coastlines, the GSW dataset was used for land-ocean classification, and these two data were used to obtain the coastal reclamation results. The Hong Kong Reclamation Map was used to produce the accuracy of the results of reclamation. 
Table 1. Detailed information on Landsat imagery and Global Surface Water (GSW) dataset used in this study.

\begin{tabular}{|c|c|c|c|c|c|c|}
\hline $\begin{array}{c}\text { Data } \\
\text { Source }\end{array}$ & \multicolumn{2}{|c|}{ Landsat Imagery } & \multicolumn{4}{|c|}{ GSW Dataset } \\
\hline $\begin{array}{l}\text { Temporal } \\
\text { span (year) }\end{array}$ & 1999-2012 & 2013-2018 & \multicolumn{4}{|c|}{ 1999-2018 } \\
\hline Sensor & $\begin{array}{l}\text { Landsat-5 } \\
\text { TM }\end{array}$ & $\begin{array}{l}\text { Landsat-8 } \\
\text { OLI }\end{array}$ & \multicolumn{4}{|c|}{ Landsat- 5,7 , and 8} \\
\hline $\begin{array}{c}\text { Number of } \\
\text { images }\end{array}$ & 56 & 24 & \multicolumn{4}{|c|}{20} \\
\hline $\begin{array}{c}\text { Type of } \\
\text { data }\end{array}$ & \multicolumn{6}{|c|}{ Raster } \\
\hline $\begin{array}{c}\text { Spatial } \\
\text { resolution }\end{array}$ & \multicolumn{6}{|c|}{$30 \mathrm{~m}$} \\
\hline $\begin{array}{l}\text { Temporal } \\
\text { resolution }\end{array}$ & \multicolumn{6}{|c|}{$16 \mathrm{~d}$} \\
\hline Value & & & 0 & 1 & 2 & 3 \\
\hline Description & & & no data & not water & $\begin{array}{c}\text { seasonal } \\
\text { water }\end{array}$ & $\begin{array}{c}\text { permanent } \\
\text { water }\end{array}$ \\
\hline
\end{tabular}

To be specific, the first data source is the Landsat imagery provided by the United States Geological Survey (USGS) (https: / / earthexplorer.usgs.gov/). Four Landsat scenes (path/row: 121/44, 121/45, 122/44, and 122/45) can cover the entire study area. In this study, 80 Landsat-5 Thematic Mapper (TM) and Landsat- 8 Operational Land Imager (OLI) images over 1999-2018 (with 4 images per year) were used. Among them, 56 Landsat-5 TM images were acquired from 1999 to 2012, and 24 Landsat-8 OLI images were acquired from 2013 to 2018. The spatial resolution of the Landsat imagery is $30 \mathrm{~m}$ and the temporal resolution is 16 days. To better extract artificial coastlines with coastal reclamation (e.g., dikes, ports, aquaculture ponds, and entertainment), cloud-free Landsat images were collected. The used Landsat images in this study had been pre-processed to L1T level (i.e., Standard Terrain Correction). The geo-registration is consistent and within prescribed tolerances (i.e., georeferencing error $<12 \mathrm{~m}$ ) (https:/ / lta.cr.usgs.gov/LETMP). The second data source is the GSW dataset, which was available in the Google Earth Engine (GEE) cloud computing platform (https://earthengine.google.com/). Specifically, the annual water classification historical images between 1999 and 2018 across our study area were collected (one image per year, a total of 20 images) from the GSW dataset. These annual water classification maps derived from 30-m Landsat-5, 7 , and 8 data have four values: 0 (i.e., no data), 1 (i.e., not water), 2 (i.e., seasonal water), and 3 (i.e., permanent water). Here, permanent water was extracted from the annual images to derive the land-ocean classification map for each year. The third data source is the Hong Kong Reclamation Map with a vector format, which is based on the coastal reclamation data provided by the Hong Kong Lands Department. The map was digitized by using Google Maps Engine for visualization and interactivity online. Thus, the Hong Kong Reclamation Map is reliable for comparison with our coastal reclamation result. This map illustrates the coastal reclamation projects on both sides of the Hong Kong Victoria Harbor and their areas between 1840 and 2018 at 10-year intervals. Here, coastal reclamation data over 2000-2009 and 2010-2018 were used to evaluate our produced coastal reclamation result.

\section{Methods}

\subsection{Land-Ocean Classification}

In this study, GEE was used to extract the permanent water layers from the GSW dataset for deriving land-water maps. However, owing to many inland water bodies 
(e.g., coastal wetlands and aquaculture ponds) in coastal zones, it is difficult to accurately distinguish land from the ocean (Figure $2 b$ ) using land-water maps derived from the permanent water layer. To solve this problem, an automatic coastline extraction method was adopted [29]. For the land-water maps, functions "imclose" and "imfill" available in MATLAB were applied to generate land-ocean maps. In Figure 2, a Landsat TM image, and a land-ocean map before and after 2003 in the Shekou Peninsula in Shenzhen $\left(113^{\circ} 50^{\prime}-113^{\circ} 57^{\prime} \mathrm{E}, 22^{\circ} 26^{\prime}-22^{\circ} 33^{\prime} \mathrm{N}\right)$ were used to demonstrate the step of generating a land-ocean map. Specifically, the reclaimed lake on the right side of the Shekou Peninsula is an inland water body, which was regarded as a water body in the original land-water map. However, it belongs to the land area after automatic coastline extraction processing. In this study, if a water body near the coastline is not directly connected to the ocean according to satellite imagery, this water body belongs to inland water rather than the ocean.
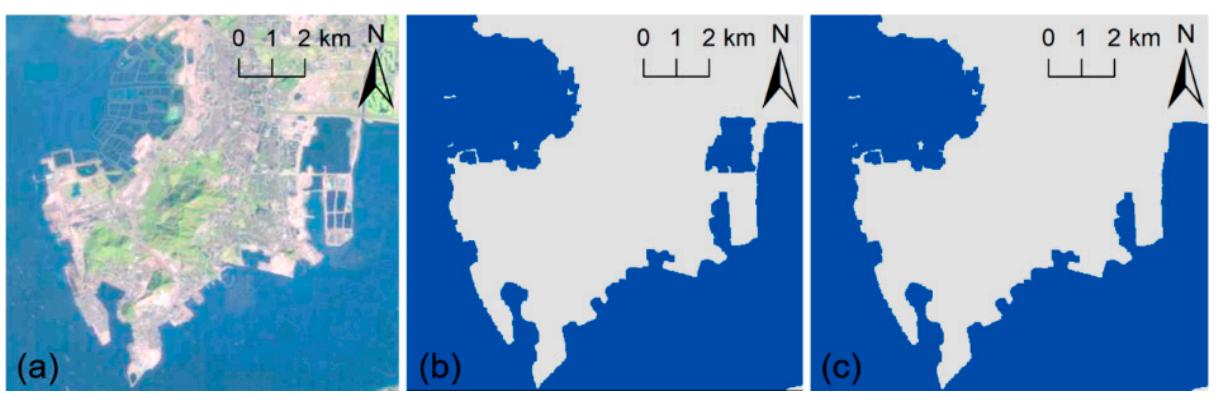

Figure 2. An example of generating a land-ocean map using Landsat data. (a) The Landsat image of Shekou Peninsula in Shenzhen in 2003; (b) the land-ocean map before automatic coastline extraction processing; and (c) the land-ocean map after automatic coastline extraction processing.

\subsection{Post-Processing of Land-Ocean Classification}

In this section, the post-processing of land-ocean classification was conducted to remove errors in our produced land-ocean maps induced by the complex landscape in coastal zones (e.g., coastal wetlands, aquaculture ponds, and ports). The specific steps were detailed as follows (Figure 3). First, coastal land expansions and coastal land fluctuations can be grouped based on their temporal changes based on our produced annual land-ocean maps over 1999-2018. Second, these coastal fluctuations induced by coastal reclamation for lakes and shoals with low distinction were manually checked and refined to obtain land-ocean maps between 1999 and 2018 with the help of the reference land-ocean map in 1999 using Google Earth software. Note that the manual checking can ensure the precision of land-ocean maps with a working resolution (i.e., scale) of about 1:60,000. Finally, for each annual land-ocean map after 1999, we subtracted the land area of last year from the land area of that year to produce the annual coastal land expansion map between 2000 and 2018.
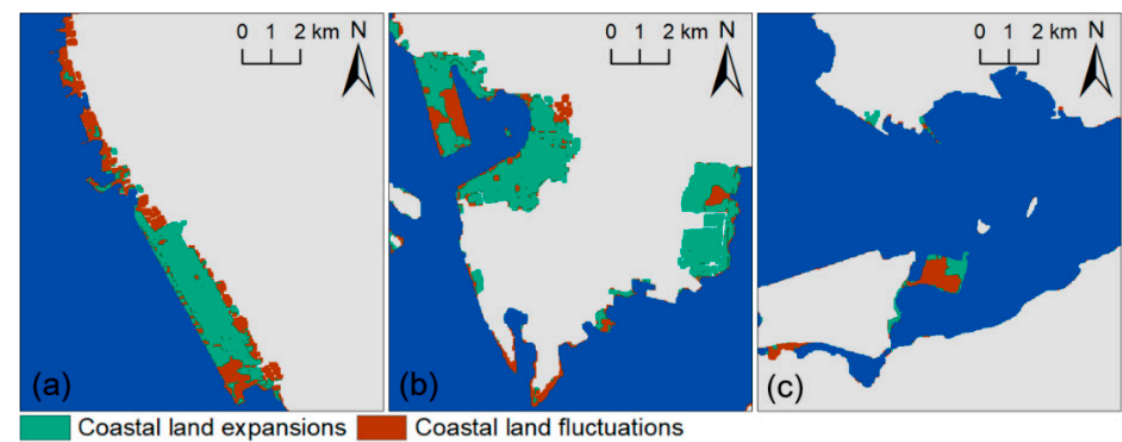

Figure 3. Coastal land expansions and fluctuations in three typical coastal areas in the study area. (a) West Coast of Bao'an District, Shenzhen; (b) Shekou Peninsula, Shenzhen; and (c) Chek Lap Kok, Hong Kong. 


\subsection{Extraction of the Coastal Reclamation}

In the study area, both natural factors (e.g., sediments from upstream rivers and sea-level rises) and coastal reclamation (e.g., dikes, ports, aquaculture ponds, and entertainment) can result in coastal land expansions [30]. Fortunately, it is easy to distinguish coastal reclamation from remote sensing images by their regular shapes. The "Raster to Polygon" function in ArcGIS was applied to obtain original annual coastal land expansion maps with a vector format. Specifically, by comparing the original result with the Landsat image for all years, natural expansion areas were removed to obtain the refined annual coastal reclamation maps in ArcGIS with a working resolution (i.e., scale) of about 1:60,000. Here, the extraction of coastal reclamation in the Shekou Peninsula, Shenzhen in 2003 $\left(113^{\circ} 56^{\prime}-113^{\circ} 57^{\prime}\right.$ E, $\left.22^{\circ} 29^{\prime}-22^{\circ} 31^{\prime} \mathrm{N}\right)$ was presented as an example in Figure 4 . To be specific, the coastline map refined in 2002 and the coastal reclamation map in 2003 (Figure 4b) were stacked on the 2003 Landsat image and the latter was refined manually in ArcGIS (Figure 4c). Then, we combined the refined coastal reclamation map with the coastline in 2002 to be the reference coastline in 2004 (Figure 4d).
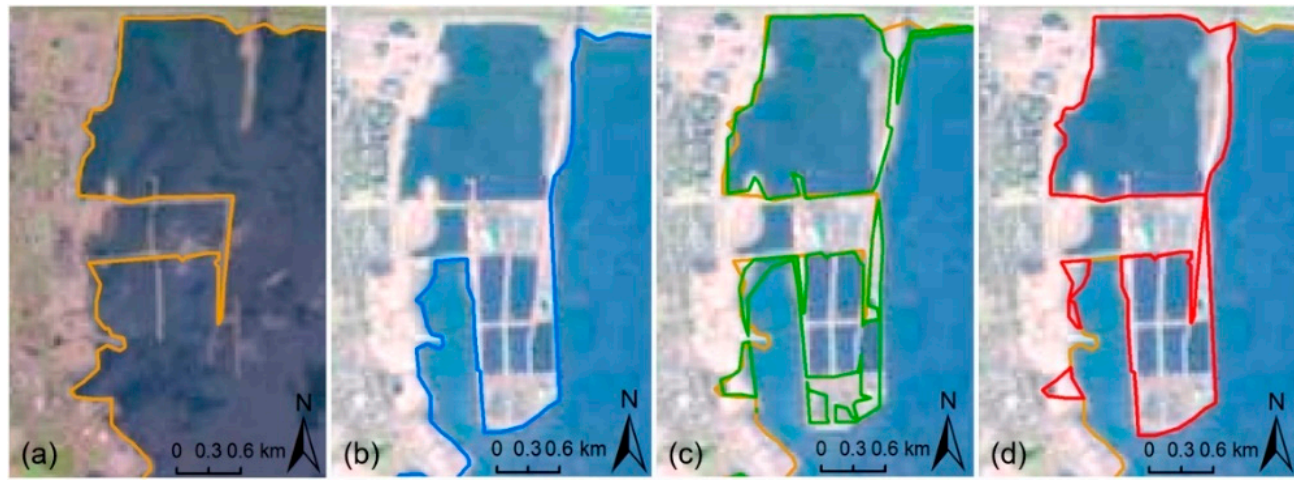

$\square$ Map of the coastline around the Shekou Peninsula in Shenzhen in 2002

$\square$ Map of the coastline around the Shekou Peninsula in Shenzhen in 2003

$\square$ Original coastal land expansion map in 2003

$\square$ Refined coastal land expansion map in 2003

Figure 4. An example of extracting coastal reclamation of one year. (a) Map of the coastline around the Shekou Peninsula in Shenzhen in 2002; (b) map of the coastline around the Shekou Peninsula in Shenzhen in 2003; (c) original coastal land expansion map in 2003; and (d) refined coastal land expansion map in 2003. For each subfigure, the basemap is the true color composition of Landsat imagery in the corresponding year.

\subsection{Assessment of the Coastal Reclamation}

We assessed the accuracy of our produced coastal reclamation dataset using the coastal reclamation data provided by the Hong Kong Lands Department [31] (i.e., Coastal Reclamation Maps on both sides of Victoria Harbor, Hong Kong, 1840-2018). To be specific, the Root Mean Square Error (RMSE) and correlation coefficient $(r)$ between coastal reclamation areas from our result and official data were calculated by the correlation analysis. RMSE and $r$ were calculated according to Equations (1) and (2). Moreover, the chi-square test $\left(x^{2}\right)$ was performed according to Equation (3) to evaluate the agreement of coastal reclamation area results between our result and official data. The Root Mean Square Error (RMSE), correlation coefficient $(r)$, and chi-square test $\left(x^{2}\right)$ were calculated as follows.

$$
\text { RMSE }=\sqrt{\frac{\sum_{i=1}^{n}\left(X_{i}-Y_{i}\right)^{2}}{n}}
$$

where $X$ is the coastal reclamation area from our result; $Y$ is the official coastal reclamation area; and $n$ is the number of areas of coastal reclamation projects used for calculation. In this 
study, four coastal reclamation projects were considered and were detailed in Section 5.2 (i.e., $n=4)$.

$$
r=\frac{\sum_{i=1}^{n}\left(X_{i}-\bar{X}\right)\left(Y_{i}-\bar{Y}\right)}{\sqrt{\sum_{i=1}^{n}\left(X_{i}-\bar{X}\right)^{2}} \sqrt{\sum_{i=1}^{n}\left(Y_{i}-\bar{Y}\right)^{2}}}
$$

where $X$ is the coastal reclamation area from our result; $Y$ is the official coastal reclamation area; and $n$ is the number of areas of coastal reclamation projects used for calculation.

$$
x^{2}=\sum_{i=1}^{n} \frac{\left(X_{i}-Y_{i}\right)^{2}}{Y_{i}}
$$

where $X$ is the coastal reclamation area from our result; $Y$ is the official coastal reclamation area; and $n$ is the number of areas of coastal reclamation projects used for calculation.

\section{Results}

\subsection{Spatial Distribution of Coastal Reclamation}

Figure 5 shows the spatial distribution of the coastal reclamation in the study area (i.e., Shenzhen and Hong Kong) from 2000 to 2018 at a 30-m spatial resolution derived from Landsat imagery and GSW dataset. Over the study period, many coastal reclamation activities were conducted in our study area, with a total area of $4140.7 \mathrm{hm}^{2}$. Coastal reclamation in the study area showed a large spatial difference. The amount of coastal reclamation in Shenzhen was much larger than that in Hong Kong. Specifically, the total coastal reclamation area in Shenzhen was $3409.8 \mathrm{hm}^{2}$ and the total coastal reclamation area in Hong Kong was $730.9 \mathrm{hm}^{2}$, about $1 / 5$ of that in Shenzhen. Six typical areas of coastal reclamation in the study area were enlarged and displayed in Figure 5 to demonstrate the details of the spatial distribution of coastal reclamation. Note that almost all the coastal reclamation projects were included in the six areas. Specifically, the sum of coastal reclamation in the six areas was $4035.4 \mathrm{~km}^{2}$, accounting for $97.5 \%$ of the total result of coastal reclamation in the study area. Then, land use information [25] and Google Maps in 2019 across this study area were integrated to interpret the types of coastal reclamation. The online Google maps can provide the name and attribution of each landscape patch, so they can be used to characterize the types of coastal reclamation. Among six areas, three areas (Figure 5a,b,f) are located in Shenzhen. Area a is located on the west coast of Baoan District, which is Shenzhen Baoan International Airport. Area $b$ is located on the southern coast of the Bao'an District and the Shekou Peninsula in the Nanshan District, which consist of harbors and residential land. Area $\mathrm{f}$ is located on the east coast of Yantian District, which is the Yantian Port. The other three areas (Figure 5c-e) are located in Hong Kong. Area c is located in Chek Lap Kok, which is an artificial island at the Hong Kong-Zhuhai-Macao Bridge. Area $\mathrm{d}$ is located on the northeast coast of Lantau Island and Tsing Yi Island, which is Hong Kong Disneyland and Container Terminal No. 9. Area e is located on both sides of Victoria Harbour and is a green space of Cultural Plaza and Hong Kong West Kowloon Station. Over the past 19 years, the largest coastal reclamation project in Shenzhen was the Shekou Peninsula Reclamation Project, with an area of $1119.4 \mathrm{hm}^{2}$. The largest coastal reclamation project in Hong Kong was the Hong Kong Disneyland construction, with an area of $263.7 \mathrm{hm}^{2}$. 

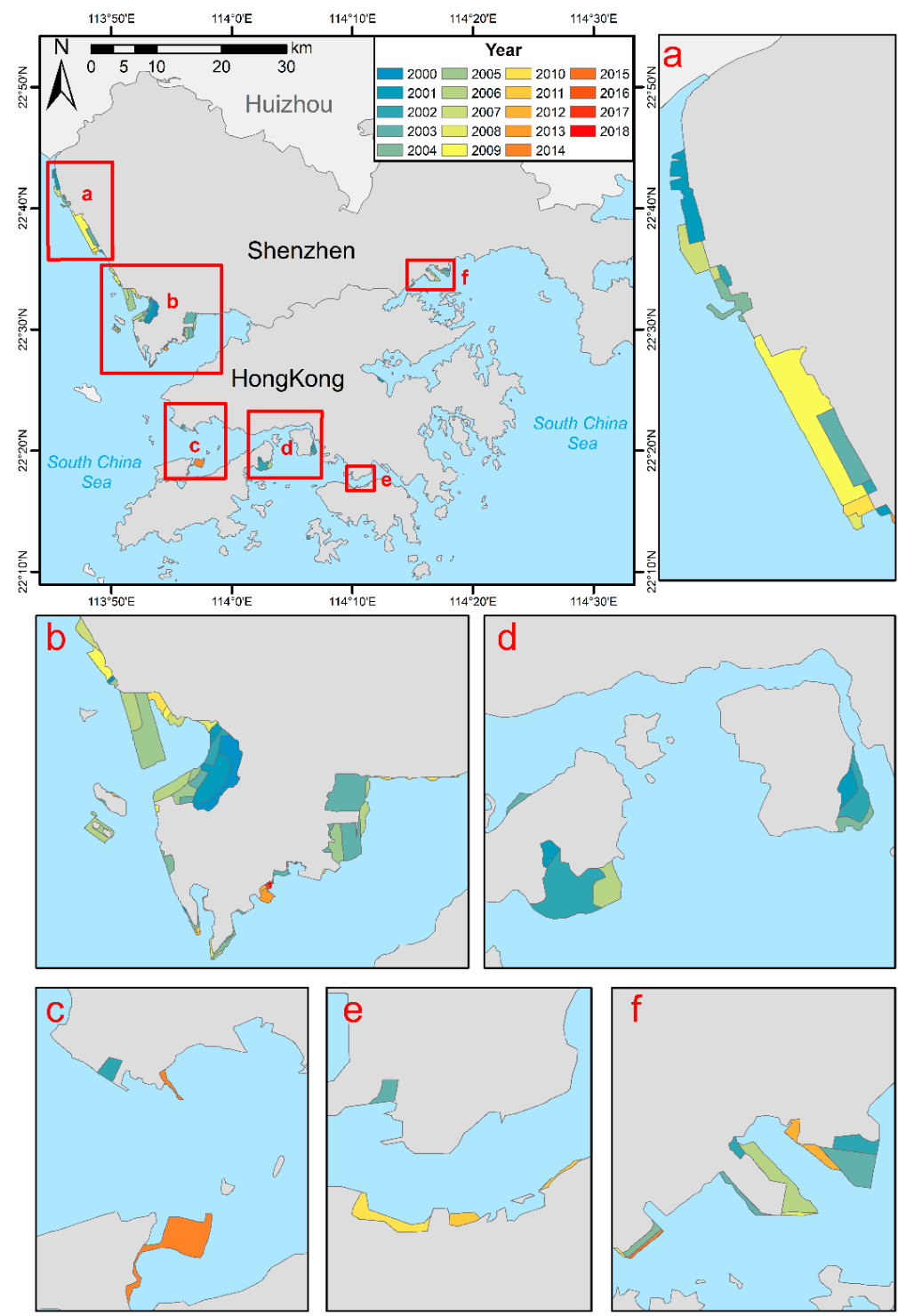

Figure 5. Spatial distribution of the coastal reclamation in Shenzhen and Hong Kong over 2000-2018. Different colors indicate coastal reclamation in different years. Six typical areas of coastal reclamation were enlarged to demonstrate the detailed information of coastal reclamation. (a) The western coast of Baoan District in Shenzhen; (b) the southern coast of Shenzhen Baoan District and the Shekou Peninsula in Nanshan District; (c) the Chek Lap Kok; (d) the northeast coast of Lantau Island and Tsing Yi Island; (e) Hong Kong Victoria Harbour; and (f) Shenzhen Yantian District East Coast.

\subsection{Temporal Changes of Coastal Reclamation}

Figure 6 shows the time series of the coastal reclamation areas and the total results in Shenzhen and Hong Kong during 2000-2018. Over the past 19 years, the temporal characteristics of the coastal reclamation in Shenzhen and Hong Kong exhibited significant differences. The total area of the coastal reclamation in Shenzhen and Hong Kong was $4140.7 \mathrm{hm}^{2}$, with an average annual coastal reclamation of $217.9 \mathrm{hm}^{2}$. The maximum coastal reclamation area of $700.4 \mathrm{hm}^{2}$ occurred in $2003\left(684.1 \mathrm{hm}^{2}\right.$ in Shenzhen and $16.3 \mathrm{hm}^{2}$ in Hong Kong). The minimum coastal reclamation area of $2.8 \mathrm{hm}^{2}$ occurred in 2017 (all in Shenzhen). Apart from 2002 and 2014, the coastal reclamation area in Shenzhen was larger than that in Hong Kong. Before 2010, coastal reclamation activities in Shenzhen were relatively frequent, with a cumulative coastal reclamation area of $3202.9 \mathrm{hm}^{2}$, accounting for $93.9 \%$ of the total area, with an average annual coastal reclamation of $320.3 \mathrm{hm}^{2}$. After 2010, coastal reclamation activities in Shenzhen decreased sharply. Specifically, the 
cumulative coastal reclamation area reached $206.9 \mathrm{hm}^{2}$, accounting for only $6.1 \%$ of its total area, with an average annual coastal reclamation of $23.0 \mathrm{hm}^{2}$. In 2002 and 2014, Hong Kong had large-scale coastal reclamation. The coastal reclamation area in 2002 and 2014 were $300.6 \mathrm{hm}^{2}$ and $201.2 \mathrm{hm}^{2}$, respectively, totaling $501.8 \mathrm{hm}^{2}$, accounting for $68.7 \%$ of the total coastal reclamation area in Hong Kong over the past 19 years. From Figure 6, we can find that the coastal reclamation in Shenzhen exhibited a temporal characteristic of "increasing slightly and then decreasing sharply" while the coastal reclamation in Hong Kong exhibited a temporal characteristic of "first decreasing and then increasing and then decreasing". To be specific, during the first 10 years, the coastal reclamation activities in Shenzhen were relatively frequent, with an average annual coastal reclamation of $320.3 \mathrm{hm}^{2}$, which decreased sharply in the following 9 years, with an average annual coastal reclamation of $23.0 \mathrm{hm}^{2}$. By comparison, the coastal reclamation in Hong Kong only occurred in $2002\left(300.6 \mathrm{hm}^{2}\right)$ and $2014\left(201.2 \mathrm{hm}^{2}\right)$. In other years, coastal reclamation activities were relatively few, with an average of $13.5 \mathrm{hm}^{2}$ per year.

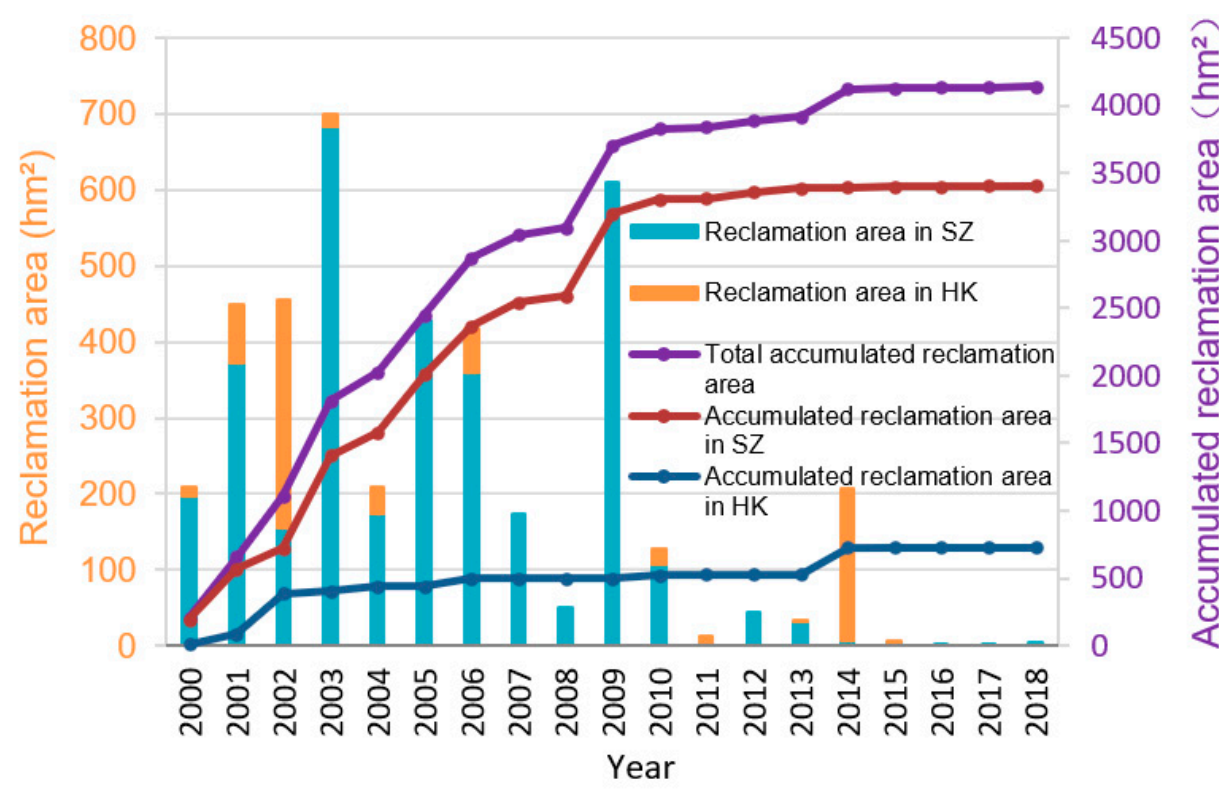

Figure 6. Time series of the coastal reclamation areas in Shenzhen and Hong Kong. The horizontal axis is the year, the left vertical axis is the annual coastal reclamation area, and the right vertical axis is the cumulative coastal reclamation area. The bar graphs are the annual coastal reclamation area in Shenzhen and Hong Kong, and the curves are the cumulative coastal reclamation area and the total coastal reclamation area in Shenzhen and Hong Kong.

To demonstrate more details of temporal changes, Table 3 and Figure 7 were presented to illustrate coastal reclamation results of Shenzhen and Hong Kong over different periods from 2000 to 2018. For Shenzhen and Hong Kong, this Table presents their respective and total reclaimed area over the past 19 years, their respective and total reclaimed area of each year, and their total coastal reclamation area every five years. From 2000 to 2018, the total coastal reclamation area in Shenzhen and Hong Kong was $4140.7 \mathrm{hm}^{2}$, with an average annual coastal reclamation of $217.9 \mathrm{hm}^{2}$. The total coastal reclamation area in Shenzhen was $3409.8 \mathrm{hm}^{2}$, with an annual average coastal reclamation of $179.5 \mathrm{hm}^{2}$, and the total coastal reclamation area in Hong Kong was $730.9 \mathrm{hm}^{2}$, with an annual average coastal reclamation of $38.5 \mathrm{hm}^{2}$, about $1 / 5$ of that of Shenzhen. As shown in Table 2 and Figure 7, Shenzhen and Hong Kong have experienced obvious coastal reclamation declines over the past 19 years. The coastal reclamation areas in 2000-2004, 2005-2009, 2010-2014, and 2015-2018 were $2022.8 \mathrm{hm}^{2}, 1681.3 \mathrm{hm}^{2}, 421.0 \mathrm{hm}^{2}$, and $15.6 \mathrm{hm}^{2}$, respectively. Coastal reclamation in Shenzhen showed a temporal characteristic of "increasing slightly and then decreasing sharply," and the areas of coastal reclamation during the four periods were $1581.2 \mathrm{hm}^{2}, 1621.8 \mathrm{hm}^{2}, 192.4 \mathrm{hm}^{2}$, and $14.5 \mathrm{hm}^{2}$, respectively. Coastal reclamation in Hong 
Kong showed a temporal characteristic of "first decreasing and then increasing and then decreasing" and the areas of coastal reclamation during the four periods were $441.6 \mathrm{hm}^{2}$, $59.5 \mathrm{hm}^{2}, 228.6 \mathrm{hm}^{2}$, and $1.2 \mathrm{hm}^{2}$, respectively.

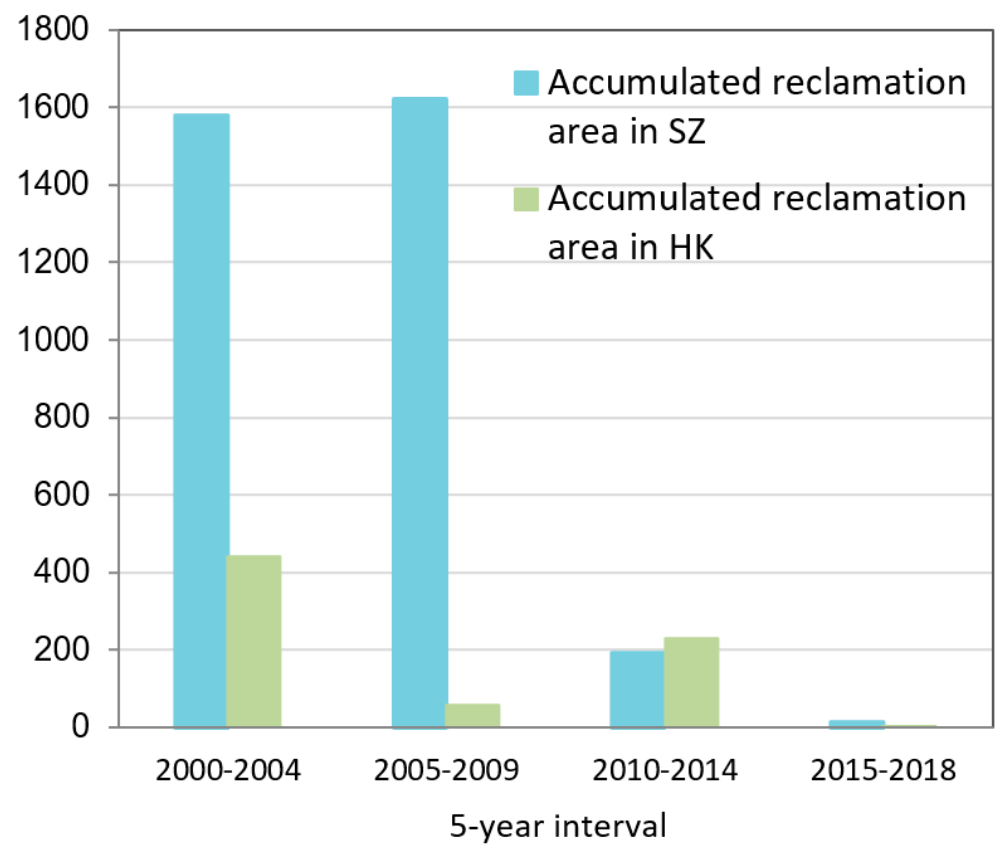

Figure 7. Accumulated areas of the coastal reclamation in Shenzhen and Hong Kong within different five-year intervals.

Table 2. Statistics for coastal reclamation areas in Shenzhen and Hong Kong.

\begin{tabular}{|c|c|c|c|c|c|c|c|c|c|c|c|c|c|c|c|c|c|c|c|c|}
\hline \multirow{2}{*}{ Regions } & \multicolumn{20}{|c|}{ Area of Reclamation $/ \mathrm{hm}^{2}$} \\
\hline & 2000 & 2001 & 2002 & 2003 & 2004 & 2005 & 2006 & 2007 & 2008 & 2009 & 2010 & 2011 & 2012 & 2013 & 2014 & 2015 & 2016 & 2017 & 2018 & Total \\
\hline Shenzhen & 197.1 & 372.8 & 154.6 & 684.1 & 172.7 & 428.3 & 359.1 & 173.4 & 51.5 & 609.5 & 106.9 & 5.1 & 43.7 & 31.1 & 5.6 & 3.8 & 3.4 & 2.8 & 4.5 & 3409.8 \\
\hline $\begin{array}{l}\text { Hong } \\
\text { Kong }\end{array}$ & 11.1 & 76.9 & 300.6 & 16.3 & 36.7 & 0 & 59.5 & 0 & 0 & 0 & 19.8 & 7.3 & 0 & 0.3 & 201.2 & 1.2 & 0 & 0 & 0 & 730.9 \\
\hline \multirow{3}{*}{ Total } & 208.2 & 449.7 & 455.1 & 700.4 & 209.4 & 428.3 & 418.6 & 173.4 & 51.5 & 609.5 & 126.7 & 12.4 & 43.7 & 31.3 & 206.8 & 4.9 & 3.4 & 2.8 & 4.5 & \multirow{3}{*}{4140.7} \\
\hline & \multicolumn{5}{|c|}{2022.8} & \multicolumn{5}{|c|}{1681.3} & \multicolumn{5}{|c|}{421.0} & \multicolumn{4}{|c|}{15.6} & \\
\hline & & & 2022.8 & & & & & 1681.3 & & & & & 421.0 & & & \multicolumn{4}{|c|}{15.6} & \\
\hline
\end{tabular}

\section{Discussion}

\subsection{Economy and Urbanization Drivers}

It is necessary to investigate the relationship between coastal reclamation and the local economy because coastal reclamation activities can affect the coastal environment [7,32]. Specifically, coastal reclamation is strongly associated with socioeconomic variables, such as GDP, population, and urbanization level. From the Shenzhen Statistical Yearbook 2019 [33] and the Hong Kong Census and Statistics Department [34], between 2000 and 2018, both Shenzhen and Hong Kong experienced rapid economic and social development. In 2000, the GDP of Shenzhen was $¥ 218.7$ billion, while the GDP of Hong Kong was \$172.7 billion. In 2018 , the GDP of Shenzhen was $¥ 2422.2$ billion, while the GDP of Hong Kong was $\$ 362.7$ billion. The growth rates are $1007.5 \%$ and $110.0 \%$ respectively. Besides, in 2000, the population of Shenzhen was 7.0 million, while the population of Hong Kong was 6.8 million. In 2018, the population of Shenzhen was 13.0 million, while the population of Hong Kong was 7.5 million. The growth rates are $85.7 \%$ and $10.3 \%$ respectively. We can confirm that there is a strong positive relationship between coastal reclamation, the local economy (i.e., GDP), and the population. Apart from GDP and population, urbanization level can also be associated with coastal reclamation. In this study, the urbanization rate 
was used to measure the urbanization level of Shenzhen and Hong Kong. From the website of the Guangdong Statistics Bureau [35] and World Bank [36], Hong Kong and Shenzhen are cities with high urbanization rates. The urbanization rate of Shenzhen was $92.46 \%$ in 2000 and reached $100 \%$ in 2010. For Hong Kong, as early as 1993, its urbanization rate has reached $100 \%$. Owing to the high urbanization rates, rapidly growing economy, and population, the Shenzhen and Hong Kong governments obtained land from the ocean for increasing industrial lands, commercial lands, construction lands, and residential lands, which resulted in an increasing demand for land area through coastal reclamation.

In summary, GDP, population, and urbanization level are associated with coastal reclamation. From Table 3, compared with Hong Kong, Shenzhen exhibited a greater increase in both economy, population, and urbanization rate from 2000 to 2018. In the future, the potential correlation between coastal reclamation events and economic-social development in coastal zones can be further examined.

Table 3. GDP, population, and urbanization rate of Shenzhen and Hong Kong in 2000 and 2018, and coastal reclamation area over 2000-2018.

\begin{tabular}{|c|c|c|c|c|c|c|}
\hline City & & Shenzhen & & & Hong Kong & \\
\hline Year (a) & 2000 & 2018 & $\begin{array}{l}\text { Growth } \\
\text { rate }\end{array}$ & 2000 & 2018 & $\begin{array}{l}\text { Growth } \\
\text { rate }\end{array}$ \\
\hline GDP (¥) & 218.7 B & 2422.2 B & $1007.5 \%$ & 172.7 B & 362.7 B & $110.0 \%$ \\
\hline Population & $7.0 \mathrm{M}$ & $13.0 \mathrm{M}$ & $85.7 \%$ & $6.8 \mathrm{M}$ & $7.5 \mathrm{M}$ & $10.3 \%$ \\
\hline $\begin{array}{l}\text { Urbanization } \\
\text { rate }\end{array}$ & $92.46 \%$ & $100 \%$ & $7.54 \%$ & $100 \%$ & $100 \%$ & 0 \\
\hline $\begin{array}{l}\text { Area of } \\
\text { reclama- } \\
\text { tion }\end{array}$ & & $3409.8 \mathrm{hm}^{2}$ & & & $730.9 \mathrm{hm}^{2}$ & \\
\hline
\end{tabular}

\subsection{Comparison with Other Data Sources}

Figure 8 shows a comparison between the coastal reclamation data obtained in this study and the Hong Kong reclamation map in the areas on both sides of Victoria Harbor from 2000 to 2018. According to our calculations, coastal reclamation areas from our study and official data are $35.4 \mathrm{hm}^{2}$ and $37.1 \mathrm{hm}^{2}$, which differ by $4.6 \%$. From Figure 8 , areas of four coastal reclamation projects from our calculations are $8.3 \mathrm{hm}^{2}, 19.8 \mathrm{hm}^{2}, 4.3 \mathrm{hm}^{2}$, and $3.0 \mathrm{hm}^{2}$, and the area of four coastal reclamation projects from official data are $8.6 \mathrm{hm}^{2}$, $21.1 \mathrm{hm}^{2}, 4.5 \mathrm{hm}^{2}$, and $2.9 \mathrm{hm}^{2}$. We can find a good agreement (RMSE $=0.72, r=0.99$ ) between coastal reclamation areas from our result and official data by correlation analysis. According to the chi-square test, our coastal reclamation data and official data exhibit a good agreement at the 0.05 significance level. It can also be seen that the spatial distribution of coastal reclamation from our study is consistent with the official data, indicating that our coastal reclamation data have high accuracy. 

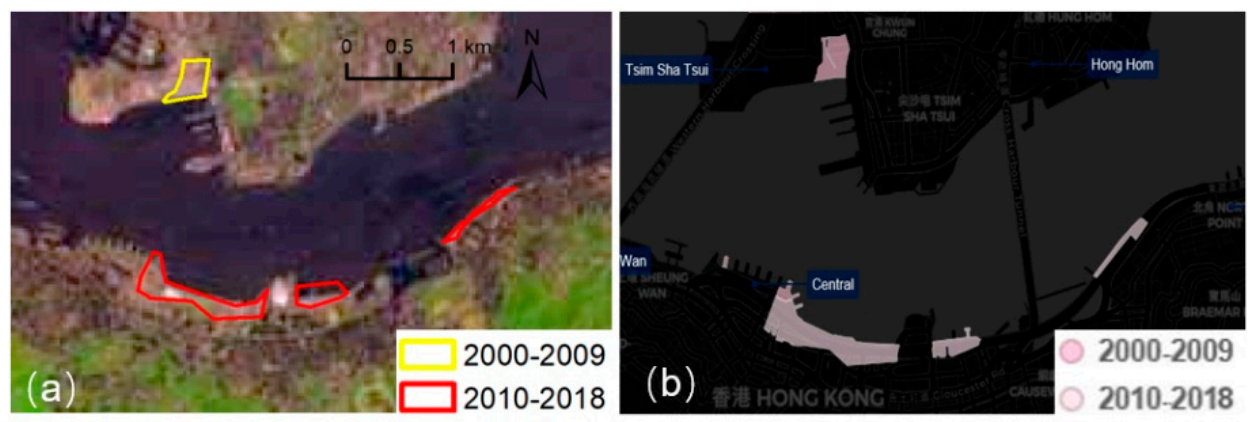

Figure 8. Comparisons between (a) our produced coastal reclamation result and (b) the Hong Kong reclamation map from official data. Figure 8a shows the selected four areas of coastal reclamation with the basemap of a Landsat image in 2018. The coastal reclamation area on the north coast of Victoria Harbor is Yau Ma Tei; the coastal reclamation area on the south coast of Victoria is Admiralty, Wan Chai, and North Point from west to east. In Figure 8a, the yellow and the red represent the coastal reclamation during 2000-2009 and 2010-2018. In Figure 8b, the pink and the light pink are the coastal reclamation projects from the Hong Kong Reclamation Map during 2000-2009 and 2010-2018.

\subsection{Future Reclamation Planning in the Study Area}

In general, we can find that national policy plays an essential role in promoting coastal reclamation activities in Shenzhen and Hong Kong. According to the Shenzhen Coastal Zone Comprehensive Protection and Utilization Plan (2018-2035) [38], from 2018 to 2035, the coastal reclamation area in Shenzhen will be concentrated on the west coast of Dakonggang New City, Bao'an District, with a total reclamation area of $1724.9 \mathrm{hm}^{2}$, mainly used for port constructions. Compared with 2000-2018, the scale of the coastal reclamation activities in Shenzhen will greatly decline, with more emphasis on coastline restoration and coastal zone development. By contrast, from 2018, Hong Kong has planned many coastal reclamation projects, such as airport city construction in the north of Hong Kong International Airport $\left(650 \mathrm{hm}^{2}\right)$, Tung Chung New Town Expansion $\left(130 \mathrm{hm}^{2}\right)$, Lantau Island Xinao Reclamation Project $\left(80 \mathrm{hm}^{2}\right)$, New Territories Longgutan Reclamation Project $\left(220 \mathrm{hm}^{2}\right)$, and Lantau Tomorrow Vision project $\left(1700 \mathrm{hm}^{2}\right)$. According to the Hong Kong Sustainable Lantau Office [39], compared with 2000-2018, the scale of the coastal reclamation activities in Hong Kong will increase significantly, mainly concentrated on the less developed Lantau and surrounding islands.

At the end of the 20th century, coastal reclamation projects in Hong Kong caused dissatisfaction among environmentalists, who believed that coastal reclamation projects were unnecessary and can destroy the coastal environment. To protect the feature of Victoria Harbor as a natural and cultural heritage and the marine ecological environment, some councilors started a series of campaigns [40]. In 1997, the "Protection of the Harbor Act Ordinance" was performed to restrict the coastal reclamation projects dominated by the Hong Kong government. In 2003, some people overturned the "Wan Chai Reclamation Plan" in the Hong Kong Court of Final Appeal. Since then, these campaigns have directly affected the future planning of coastal reclamation in Hong Kong. As a result, more than $600 \mathrm{hm}^{2}$ of planned coastal reclamation in Hong Kong has been "deleted" [40], resulting in fewer coastal reclamation projects than Shenzhen in the 21st century. After 2018, to promote economic development and solve the housing tension problem, the Hong Kong government has put forward a series of coastal reclamation plans under pressure from protests. These plans will greatly increase the amount of coastal reclamation in Hong Kong in the future. The policy of the Shenzhen government is different from Hong Kong. According to the China Academy of Urban Planning and Design Shenzhen [41], Shenzhen released the "Shenzhen City Master Plan (2010-2020)" to protect the coastal environment in Shenzhen in 2010, and there were few planned coastal reclamation projects. The shift of planning agreed well with the decline of coastal reclamation in Shenzhen before and after 2010 (Table 3 and Figure 7). 
In addition, it is important to understand the future reclamation development policies to better monitor the future reclamation development of Shenzhen and Hong Kong using satellite data. According to the Shenzhen Coastal Zone Comprehensive Protection and Utilization Plan (2018-2035), Shenzhen will pay more attention to strengthening the protection and restoration of habitats and improving the ecological service function after 2018. As a consequence, the coastal reclamation area will be further reduced in the future. Overall, under the current and future coastal reclamation planning in Shenzhen and Hong Kong, the area of coastal reclamation in Hong Kong will exceed that in Shenzhen. Therefore, in the coming decades, it will be necessary to continuously monitor the coastal reclamation in Shenzhen and Hong Kong to provide an accurate and updated dataset for better understanding and evaluating the role of coastal reclamation related policies in coastal environmental changes.

\section{Conclusions}

In this study, we monitored annual coastal reclamation in Shenzhen and Hong Kong since the 21st century and obtained several conclusions. First, the method based on Landsat imagery and GSW dataset in this study could be applied to monitor coastal reclamation at the annual scale. Second, according to our results derived from our method, a large-scale coastal reclamation in Shenzhen and Hong Kong with a total coastal reclamation area of $4140.7 \mathrm{hm}^{2}$ over 2000-2018 could be observed. Shenzhen and Hong Kong have exhibited different temporal characteristics in coastal reclamation since the 21st century. The area of coastal reclamation in Shenzhen (i.e., $3409.8 \mathrm{hm}^{2}$ ) was much larger than that in Hong Kong (i.e., $730.9 \mathrm{hm}^{2}$ ). In addition, coastal reclamation in Shenzhen exhibited a significant declining trend. Third, as coastal reclamation is dominated by policies, it is necessary to produce an accurate and updated dataset on coastal reclamation from satellite data to further investigate coastal reclamation related environmental issues and feedback to policy-making in the future. For example, coastal reclamation may result in coastal land subsidence, which can increase the vulnerability of coastal zones especially in the context of rising sea levels. An accurate and updated dataset on coastal reclamation could be used to guide the coastal land use planning to avoid the coastal area with a higher vulnerability. Moreover, by benefiting from the global coverage and free access to Landsat and GSW datasets, this method can be extended to the globe in the future. Furthermore, our method could be extended to an earlier year to provide a longer history of coastal reclamation.

Author Contributions: T.F. contributed to the data collecting, analyzing and writing of this study. N.X. contributed to the overall idea and editing of this study. All authors have read and agreed to the published version of the manuscript.

Funding: This research was funded by Nanjing Normal University Startup Research Foundation (184080H202B254) and the National Key Research and Development Plan (2017-YFC-1405500).

Institutional Review Board Statement: “Not applicable” for studies not involving humans or animals. Informed Consent Statement: “Not applicable” for studies not involving humans.

Data Availability Statement: The data presented in this study are available on request from the corresponding author.

Acknowledgments: The authors thank the data distribution agencies who provided the publicly released data used in this study. The Landsat imagery provided by the United States Geological Survey (USGS). The GSW dataset was obtained from Google Earth Engine (GEE) cloud computing platform. The Hong Kong Reclamation Map based on the coastal reclamation data was provided by the Hong Kong Lands Department.

Conflicts of Interest: The authors declare no conflict of interest. 


\section{References}

1. Wei, Y.D.; Ye, X. Urbanization, urban land expansion and environmental change in China. Stoch. Environ. Res. Risk Assess. 2014, 28, 757-765. [CrossRef]

2. Hoeksema, R.J. Three stages in the history of land reclamation in the Netherlands. Irrig. Drain. 2007, 56, 113-126. [CrossRef]

3. Tomasicchio, G.R.; D'Alessandro, F.; Musci, F. A multi-layer capping of a coastal area contaminated with materials dangerous to health. Chem. Ecol. 2010, 26, 155-168. [CrossRef]

4. Suzuki, T. Economic and geographic backgrounds of land reclamation in Japanese ports. Mar. Pollut. Bull. 2003, 47, 226-229. [CrossRef]

5. Pui, S.K. 100 years of foreshore reclamation in Singapore. Coast. Eng. 1987, 1986, 2631-2636.

6. Yu, H.M. China's coastal ocean uses: Conflicts and impacts. Ocean Coast. Manag. 1994, 25, 161-178. [CrossRef]

7. Tian, B.; Wu, W.; Yang, Z.; Zhou, Y. Drivers, trends, and potential impacts of long-term coastal reclamation in China from 1985 to 2010. Estuar. Coast. Shelf Sci. 2016, 170, 83-90. [CrossRef]

8. Huang, J.M.; Huang, R.Q.; Jiao, J.J. Speciation and mobility of heavy metals in mud in coastal reclamation areas in Shenzhen, China. Environ. Geol. 2007, 53, 221-228. [CrossRef]

9. Wang, W.; Liu, H.; Li, Y.; Su, J. Development and management of land reclamation in China. Ocean Coast. Manag. 2014, 102, 415-425. [CrossRef]

10. Guo, H.P.; Jiao, J.J. Impact of coastal land reclamation on ground water level and the sea water interface. Groundwater 2007, 45, 362-367. [CrossRef]

11. Zhu, G.R.; Xu, X.G. Research review on environmental effects of land reclamation from sea. Ecol. Environ. Sci. 2011, 20, 761-766.

12. Qian, J.; Peng, Y.; Luo, C.; Wu, C.; Du, Q. Urban land expansion and sustainable land use policy in Shenzhen: A case study of China's rapid urbanization. Sustainability 2016, 8, 16. [CrossRef]

13. Yu, H.B.; Mo, D.W.; Wu, J.S. Study on the dynamic changes and driving forces based on remote sensing images of land reclamation in Shenzhen. Prog. Geogr. 2009, 28, 584-590.

14. Chen, M.T. The impact of reclamation on the urban design of Hong Kong. World Archit. 2007, 12, 137-139.

15. Yang, $\mathrm{H}$. The legal practice of land reclamation in Hong Kong and its reference. Law Sci. 2013, 1, 44-51.

16. Hong, Y.; Zhou, Y.Y.; Shen, S.Q.; Zhou, K. On dynamic changes of reclamation and its causes in Shenzhen during 1979 and 2014 based on remote sensing and GIS technology. Mar. Dev. Manag. 2016, 3, 89-93.

17. Wu, X.L.; Liu, C.X.; Wu, G.F. Spatial-temporal analysis and stability investigation of coastline changes: A case study in Shenzhen, China. IEEE J. Sel. Top. Appl. Earth Obs. Remote Sens. 2017, 11, 45-56. [CrossRef]

18. Fung, T. Land use and land cover change detection with Landsat MSS and SPOT HRV data in Hong Kong. Geocarto Int. 1992, 7, 33-40. [CrossRef]

19. Xu, N.; Gong, P. Significant coastline changes in China during 1991-2015 tracked by Landsat data. Sci. Bull. 2018, 63, 883-886. [CrossRef]

20. Hou, X.; Wu, T.; Hou, W.; Chen, Q.; Wang, Y.; Yu, L. Characteristics of coastline changes in mainland China since the early 1940 s. Sci. China Earth Sci. 2016, 59, 1791-1802. [CrossRef]

21. Meng, W.; Hu, B.; He, M.; Liu, B.; Mo, X.; Li, H.; Wang, Z.; Zhang, Y. Temporal-spatial variations and driving factors analysis of coastal reclamation in China. Estuar. Coast. Shelf Sci. 2017, 191, 39-49. [CrossRef]

22. $\mathrm{Wu}, \mathrm{T}$.; Hou, X.; Xu, X. Spatio-temporal characteristics of the mainland coastline utilization degree over the last 70 years in China. Ocean Coast. Manag. 2014, 98, 150-157. [CrossRef]

23. Pekel, J.F.; Cottam, A.; Gorelick, N.; Belward, A.S. High-resolution mapping of global surface water and its long-term changes. Nature 2016, 540, 418-422. [CrossRef] [PubMed]

24. Overview of Shenzhen. Shenzhen Government Online, 2019. Available online: http://www.sz.gov.cn/cn/zjsz/gl/content/post_ 1377433.html (accessed on 18 June 2020).

25. Qin, P.; Chen, J.F. A comparative study on intensive land use in Shenzhen and Hong Kong. Geogr. Res. 2011, 30, 1129-1136.

26. The Government of the Hong Kong Special Administrative Region. Available online: https://www.landsd.gov.hk/ (accessed on 21 June 2020).

27. Hong Kong Monthly Digest of Statistics May 2019. Census and Statistics Department, 2019. Available online: https://www. censtatd.gov.hk/home.html (accessed on 21 June 2020).

28. Lee, G.K.; Chan, E.H. Factors affecting urban renewal in high-density city: Case study of Hong Kong. J. Urban Plan. Dev. 2008, 134, 140-148. [CrossRef]

29. Zhang, H.; Zhang, B.; Guo, H.; Lu, J.; He, H. An automatic coastline extraction method based on active contour model. In Proceedings of the 2013 21st International Conference on Geoinformatics, Kaifeng, China, 20-22 June 2013; pp. 1-5.

30. Ren, Z.M.; Yi, H.; Ruan, M.H. Remote Sensing Survey of Shenzhen Shoreline Resources. Urban Surv. 2018, 1, 45-51.

31. Hong Kong Reclamation Map. Hong Kong Lands Department. Available online: http:/ / oldhkphoto.com/ coast/ (accessed on 22 June 2020).

32. Chen, W.; Wang, D.; Huang, Y.; Chen, L.; Zhang, L.; Wei, X.; Sang, M.; Wang, F.; Liu, J.; Hu, B. Monitoring and analysis of coastal reclamation from 1995-2015 in Tianjin Binhai New Area, China. Sci. Rep. 2017, 7, 1-12. [CrossRef] [PubMed]

33. Shenzhen Statistical Yearbook 2019, Shenzhen China. 2019. Available online: http:/ /www.sz.gov.cn/cn/ (accessed on 21 June 2020). 
34. Hong Kong Census and Statistics Department. Available online: https://www.censtatd.gov.hk/hkstat/index_tc.jsp (accessed on 22 June 2020).

35. Analysis on the Development of Population Urbanization in Guangdong. Guangdong Statistics Bureau, 2014. Available online: http:/ / stats.gd.gov.cn/tjfx/content/post_1435211.html (accessed on 18 July 2020).

36. Prospects of Urbanization in the World. World Bank. Available online: https://data.worldbank.org.cn/indicator/SP.URB.TOTL. IN.ZS (accessed on 5 July 2020).

37. Fay, M.; Opal, C. Urbanization without Growth: A Not-So-Uncommon Phenomenon; The World Bank: Washington, DC, USA, 1999.

38. Shenzhen Coastal Zone Comprehensive Protection and Utilization Plan (2018-2035). 2019. Available online: http:/ / www.sz.gov. cn/szzt2010/wgkzl/jcgk/jchgk/content/post_1319782.html (accessed on 8 July 2020).

39. Lantau Tomorrow Vision. Hong Kong Sustainable Lantau Office. Available online: https://www.lantau.gov.hk/tc/lantautomorrow-vision/index.html (accessed on 8 July 2020).

40. Ng, M.K. Power and rationality: The politics of harbour reclamation in Hong Kong. Environ. Plan. C 2011, 29, 677-692. [CrossRef]

41. Shenzhen City Master Plan (2010-2020). China Academy of Urban Planning and Design Shenzhen, 2010. Available online: http:/ / www.szcaupd.com/project-ztgh-i_11235.htm (accessed on 22 June 2020). 